\title{
Study on Sintered Ceramic Process Based on Thermal Analysis
}

\author{
Xiumei Wu \\ School of Art Design, Jingdezhen Ceramic Institute, China
}

\begin{abstract}
The sintered process is an important link of ceramic, ultra high temperature materials in the production process. Therefore, studied the sintered ceramic process based on the thermal analysis and discussed the sintering properties of ceramic materials. At first, it introduced the sintered ceramic and thermoanalysis technology. Then, described the experimental materials and characterization methods of this experiment. At the end, it used the dilatometers to determine the sintering temperature range of the ceramic. It verifies dilatometers reliability to determine the sintering ceramic temperature range. Then, heat analysis study on sintering characteristics of ceramic materials, heating rate relation with optimum sintering temperature, and the ratio of particle size distribution effect on sintering performance. The main conclusion as following: 1) by using the dilatometers, the ceramics sintering temperature range is accurate and reliable. 2) The sintering process mainly physical and chemical changes of the ceramic body are: Room temperature $300^{\circ} \mathrm{C}$, excluding dry does not eliminate residual moisture. At $300^{\circ} \mathrm{C}-1000^{\circ} \mathrm{C}$, the body weight loss significantly, no significant changes in volume. Kaolinite gradually transformed into metakaolin. At $1000^{\circ} \mathrm{C}$ to sintering temperature, the body begins to shrink. With the increase of temperature, it caused severe contraction of the body densification. When the temperature is higher than the sintering temperature, the body begins to swell. 3) The heating rate is higher; the best ceramic firing temperature is high.
\end{abstract}

KEYWORD: Ceramic material; Sintering process; Thermoanalysis technology

\section{INTRODUCTION}

Thermoanalysis technology is a kind of technology depends on the relationship between physical properties and temperature measurement in the material under the temperature control program (Wang $\mathrm{M}$ et al, 2012). Sintering process plays an important role in production process of ceramics, cement clinker, refractory materials, powder metallurgy, and ultrahigh temperature materials. Sintering process is the ceramic body heat treatment under certain conditions to make a qualitative change (Deng X L et al, 2014), and become the ceramic products. The body through a series of physical and chemical changes in this process (Wang B et al, 2013) (Sivakumar S et al, 2014), formed the phase composition and microstructure, and obtained the desired performance index. The firing process affects the microstructure, grain size and distribution of pore size and volume fraction of grain boundary (Park W U et al, 2013), thus affecting the performance of ceramic materials. Therefore, it is benefit to understand and analyze the physical and chemical changes during sintered ce- ramics process temperature for making reasonable ceramic sintering system.

\section{RESEARCH}

\subsection{Analysis of sintering ceramic materials and thermoanalysis technology}

The sintering type is generally divided into sintering solid phase and sintering liquid phase.

Sintering solid phase: It occurred between the simple solid-phase of sintering process. It refers to one or more solid (oxides, nitrides, clay) powder molding to densification shrinkage at a certain temperature after heating. Due to the solid state molecular (or atomic) attract each other. It made the powder particles bond. After the powder material migration intensity, it leads to the densification and recrystallization. It transferred to the hard and dense sintered body which has a certain geometric shape and properties under the below the melting temperature.

Sintering liquid phase: Those who have participated in the sintering liquid phase are called sinter- 
ing liquid phase. It refers to the sintering temperature exceeds the powder in the fusible component or low melting point eutectic mixture, and has certain amount of liquid phase by mass transfer to achieve the volume shrinkage and densification process.

Thermoanalysis is the combination of the principle of thermal physical properties or components. According to the International Association Thermoanalysis definition of the thermoanalysis in 1977, thermoanalysis is a kind of technology depends on the relationship between physical properties and temperature measurement in the material under the temperature control program. The "program control temperature" refers to the fixed rate of heating or cooling. "Physical properties" includes material quality, temperature, enthalpy, and size, mechanical, acoustic, electrical and magnetic properties.

\subsection{The experimental method and characterization}

In this experiment, the main raw material used for the ceramic body, the number of samples and the chemical composition are shown in Table 1. The initial particle size of sample blank material is shown in Table 2 . The body mass size distribution as shown in Figure 1.

Table 1 chemical composition of bodies

\begin{tabular}{|l|c|l|l|l|l|l|l|}
\hline \multirow{2}{*}{$\begin{array}{l}\text { Embryo } \\
\text { type }\end{array}$} & \multicolumn{6}{|c|}{ chemical composition/wt\% } \\
\cline { 2 - 8 } & $\mathrm{SiO}_{2}$ & $\mathrm{Al}_{2} \mathrm{O}_{3}$ & $\mathrm{Fe}_{2} \mathrm{O}_{3}$ & $\mathrm{TiO}_{2}$ & $\mathrm{RO}$ & $\mathrm{R}_{2} \mathrm{O}$ & $\mathrm{I} . \mathrm{L}$ \\
\hline $\begin{array}{l}\text { Daily-use } \\
\text { porcelain } \\
\text { body }\end{array}$ & 64.0 & 32.0 & 1.96 & - & 2.16 & 3.04 & 3.16 \\
\hline
\end{tabular}

Table 2 grain size parameters of ceramic body

\begin{tabular}{|l|l|l|l|l|l|}
\hline Embryo type & $\mathrm{D}_{10}$ & $\mathrm{D}_{50}$ & $\mathrm{D}_{75}$ & $\mathrm{D}_{90}$ & $\mathrm{D}(4,3)$ \\
\hline Daily-use porcelain body & 1.49 & 4.15 & 6.12 & 7.98 & 4.52 \\
\hline
\end{tabular}

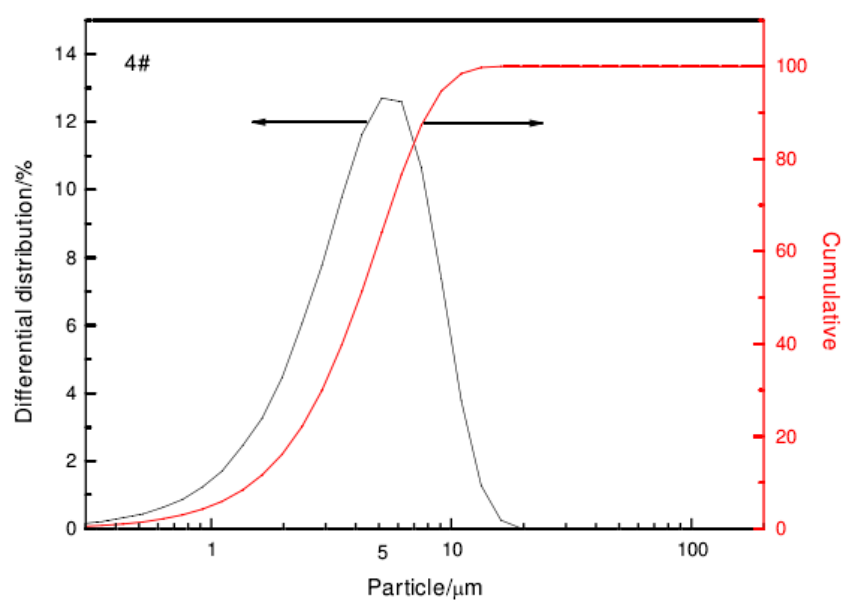

Figure 1 the size distribution of ceramic blank

(1) Test and characterization of performance

In this experiment, we used the refractoriness tester test sintering temperature range of sample, the heating rate at $5^{\circ} \mathrm{C} / \mathrm{min}$. It recorded the shrinkage of ceramic body at different temperature, and drawing thermal expansion / contraction curve under the visual observation. It determined the sintering temperature range of ceramic body according to the curve. Tested of thermal expansion curve and sintering temperature range by thermal expansion. The heating rate is $5^{\circ} \mathrm{C} / \mathrm{min}$, from room temperature to $900^{\circ} \mathrm{C}$. Then the heating rate is $1^{\circ} \mathrm{C} / \mathrm{min}, 2^{\circ} \mathrm{C} / \mathrm{min}$, $3^{\circ} \mathrm{C} / \mathrm{min}, 5^{\circ} \mathrm{C} / \mathrm{min}$ and $10^{\circ} \mathrm{C} / \mathrm{min}$, respectively, from $900^{\circ} \mathrm{C}$ to $1350^{\circ} \mathrm{C}$.According to the thermal expansion curve, it determined the ceramic body the best sintering temperature and sintering temperature range. The integrated thermal ceramic body was analyzed by differential scanning calorimeter and thermogravimetric analysis. The volume density and open porosity tested by Archimedes drainage method after sintering. The bending strength by three point bending test of various ceramic samples, the use of instruments is the WDW-200 electronic universal material test machine. Each sample was tested five times, and averaged the numerical value. The laser particle size analyzer tested the size and distribution of laser particle ceramic material, each sample test for measuring the average of the 5 as the final test results.

\section{STUDY ON SINTERING PROPERTIES OF CERAMICS}

\subsection{Dilatometer test the curve of sintering ceramic body}

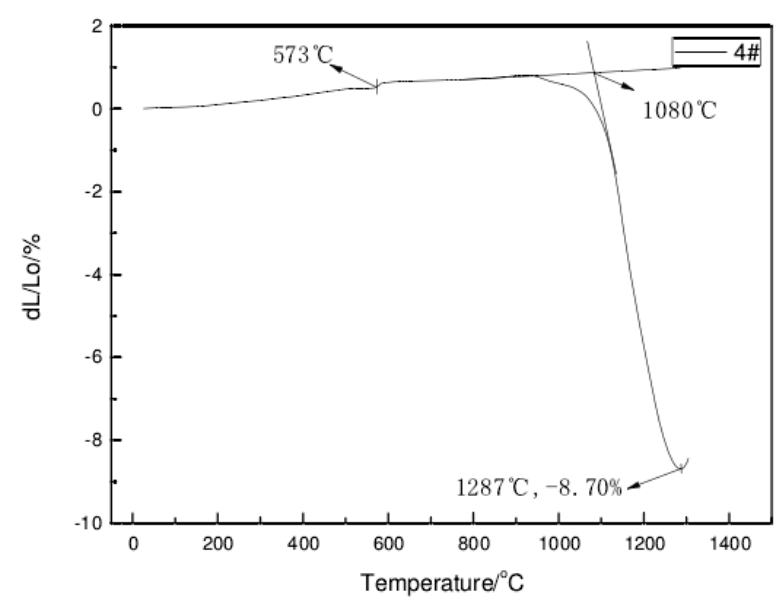

Figure 2 Ceramic body thermal Expansion curve

Figure 2 is the ceramic body (4\# sample) thermal expansion curve. It can be seen from the figure that $573^{\circ} \mathrm{C}$ in the near body obviously slight expansion. From the beginning of the $1080^{\circ} \mathrm{C}$, the body produces severe contraction. Contraction at $1287^{\circ} \mathrm{C}$ rate reaches the maximum value of $8.70 \%$. Figure 3 shows the sample at high temperature of thermal expansion curve. From the figure is not difficult to find the sample tends to be stable at $1273^{\circ} \mathrm{C}$. In $1300^{\circ} \mathrm{C}$, 
with the expansion of the sample, the temperature continues to rise, the rapid expansion of the body burning phenomenon occurred. Therefore, it is not difficult to determine the sintering temperature appropriate range of the sample is $1273^{\circ} \mathrm{C}$ to $1300^{\circ} \mathrm{C}$.

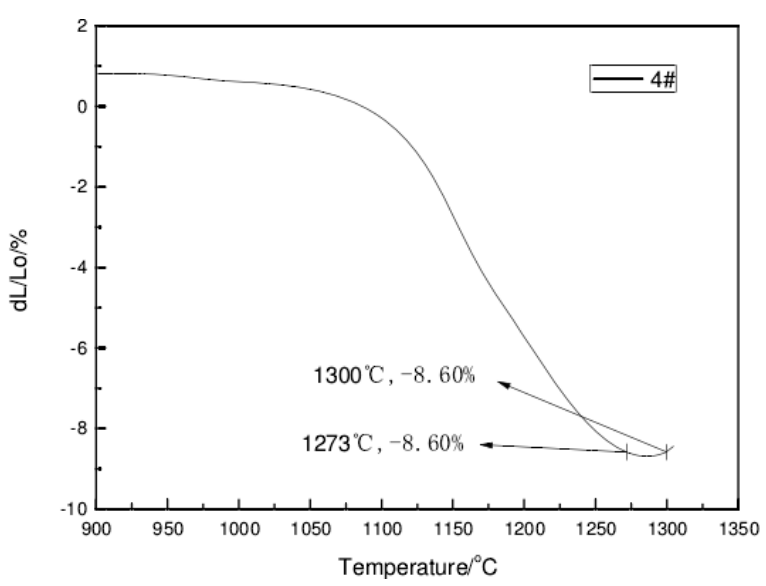

Figure 3 Ceramic body high temperature thermal expansion curve

Compared with the building ceramics (sintering temperature range: $1237^{\circ} \mathrm{C}$ to $1257^{\circ} \mathrm{C}$ ), the range of sintering temperature of ceramic body is relatively high, large firing shrinkage. The sintering temperature range is relatively narrow, only $27^{\circ} \mathrm{C}$ (sintering temperature range of porcelain body is about $50^{\circ} \mathrm{C}$ ).

\subsection{Physical and chemical changes in the sintering process of ceramic body}

Figure 4 and figure 5 are the ceramic body of the differential scanning calorimeter (DSC) and thermogravimetric curve (TG curve). The sample from room temperature to $200^{\circ} \mathrm{C}$ with a small amount of weight loss from TG curve. Due to loss of body absorbed water. The main weight loss stage of the sample was $435^{\circ} \mathrm{C}$ to $635^{\circ} \mathrm{C}$. The sample of the total loss rate was $4.57 \%$.

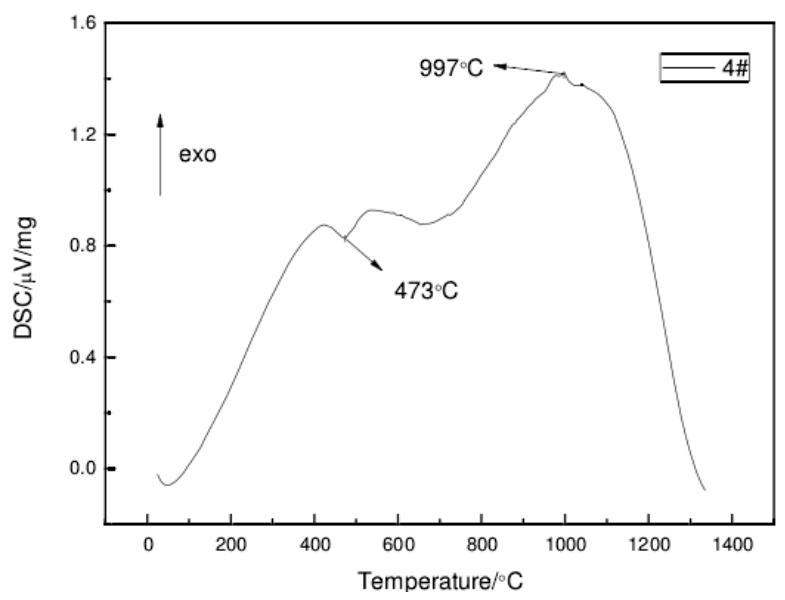

Figure 4 The DSC curve of ceramic body

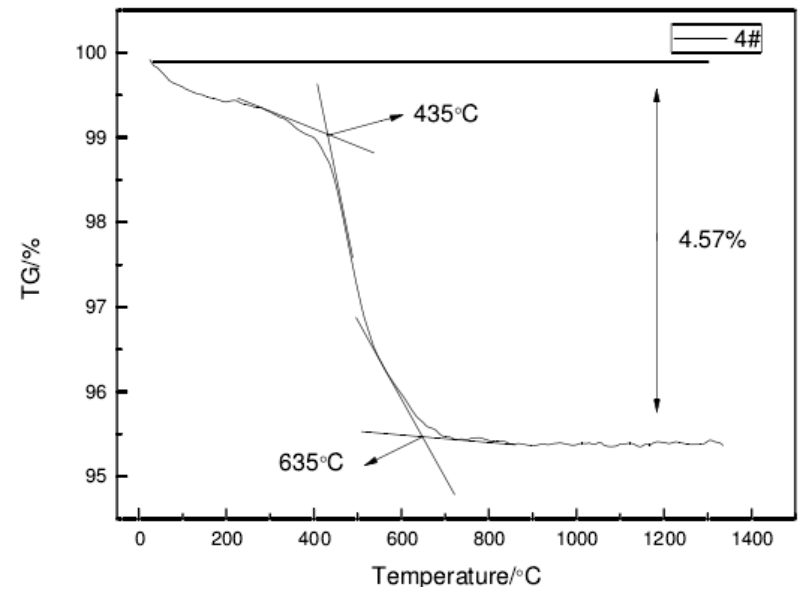

Figure 5 TG curve

Ceramic body the main physical and chemical changes in the sintering process are: room temperature is $200^{\circ} \mathrm{C}$, it mainly the residual does not exclude residual moisture when exclusion of dry. $400^{\circ} \mathrm{C}$ to $950^{\circ} \mathrm{C}$, with the exclusion of the structure of the water, the decomposition of carbonates and sulfates. The body weight loss, volume had no obvious change, the body of kaolinite transformation into pianlinite. $950^{\circ} \mathrm{C}$ to sintering temperature, the body gradually shrink. As the temperature rises to $1080^{\circ} \mathrm{C}$, the body begins to produce severe contraction of the body densification. When the temperature is higher than the sintering temperature, the body began to swell.

\subsection{Sintering temperature range measuring ceramic body with refractoriness.}

Figure 6 is the determination of ceramic body was measured with refractoriness (4\# sample) sintering shrinkage curve.

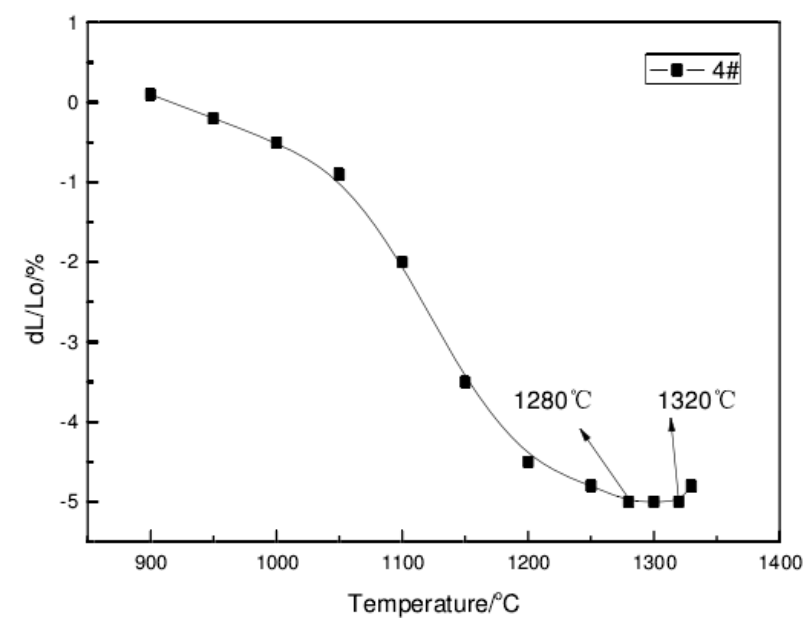

Figure 6 the curve of refractoriness test ceramic body expansion curve

The sample stops shrinking at $1280^{\circ} \mathrm{C}$. Expansion started at $1320^{\circ} \mathrm{C}$. The range of sintering temperature of the sample is $1280^{\circ} \mathrm{C}$ to $1320^{\circ} \mathrm{C}$. 


\subsection{The performance of the sintered ceramic body}

(1) Sintering temperature effect on ceramic open porosity and volume density

The sintering temperature affects the volume density and the porosity of sintered ceramics. Figures 7 and 8 are the sintering temperature related to the open porosity and volume density.

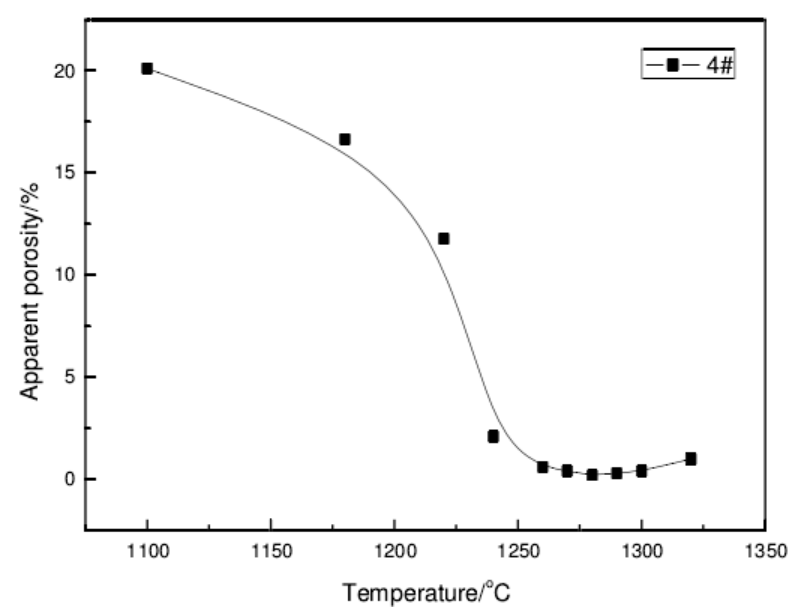

Figure 7 the relationship between the porosity and sintering temperature of the ceramics samples

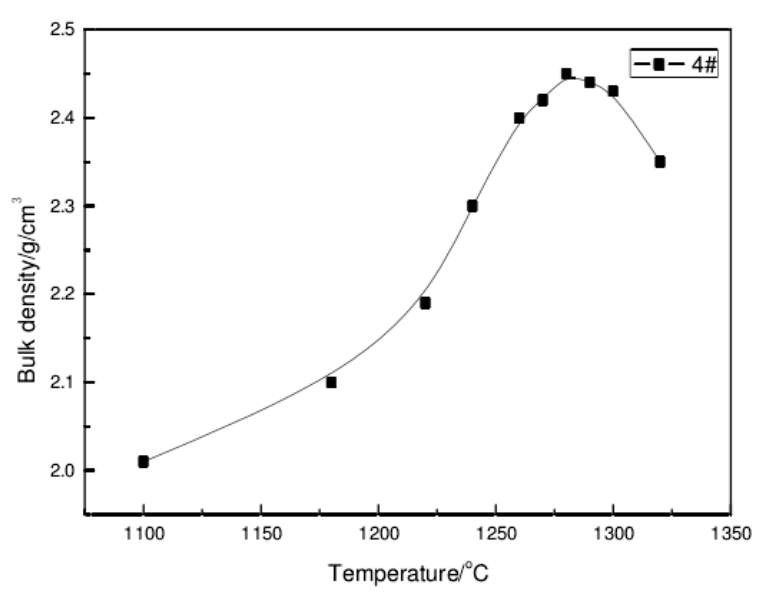

Figure 8 the relationship between volume density and sintering temperature of the ceramics samples

Ceramic samples open porosity tended to zero at $1260{ }^{\circ} \mathrm{C}$ to $1270^{\circ} \mathrm{C}$ from figure 7 . At $1280^{\circ} \mathrm{C}$, the sample open porosity reaches the minimum value, $0.21 \%$. Figure 8 shows the results of volume density. The sample tends to a maximum value at $1270^{\circ} \mathrm{C}$ to $1280^{\circ} \mathrm{C}$. At $1280^{\circ} \mathrm{C}$, the volume density of the sample is $2.450 \mathrm{~g} / \mathrm{cm}^{3}$. Ceramic samples suitable sintering temperature is $1270-1300^{\circ} \mathrm{C}$ from figure7 and figure 8 .

(2) Sintering temperature effects on the flexural strength of ceramic

Figure 9 shows the daily ceramic samples (4\#) of the bending strength and sintering temperature. Ceramic samples with the sintering temperature in- creasing, the flexural strength increases first and then decreases. At $1270-1300^{\circ} \mathrm{C}$, small changes in the flexural strength of samples, and reached the maximum value $88 \mathrm{MPa}$ at $1280^{\circ} \mathrm{C}$.

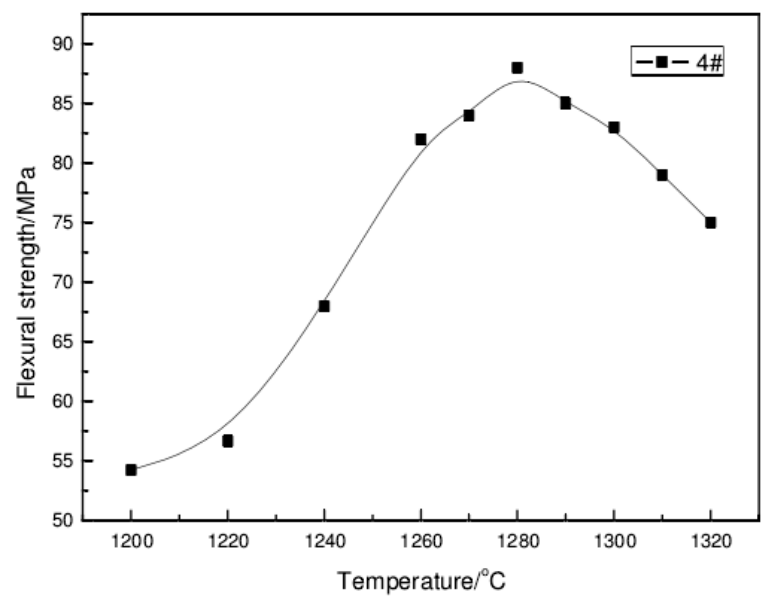

Figure 9 the relationship between anti bending strength and sintering temperature of the ceramic samples

\subsection{Heating rate effect on the ceramic sintering temperature}

Figure 10 shows the daily ceramic samples the optimum sintering temperature (shrinkage maximum temperature) and the heating rate. Samples of the optimum sintering temperature Ts (c) and V (C /min) heating rate: $\mathrm{Ts}=\mathrm{AlgV}+\mathrm{B}$. In this experiment, the samples of $\mathrm{A}$ is $60, \mathrm{~B}$ is $1243, \mathrm{~V} \leqq 10$, Ts $=60 \lg \mathrm{V}$ +1243 . The results show that the heating rate is higher. The best ceramic firing temperature is high. The value of A can reflect the sensitivity of the optimum sintering temperature heating rate on the ceramic body. The larger the value of $\mathrm{A}$ is the heating rate on the sintering temperature the greater the impact.

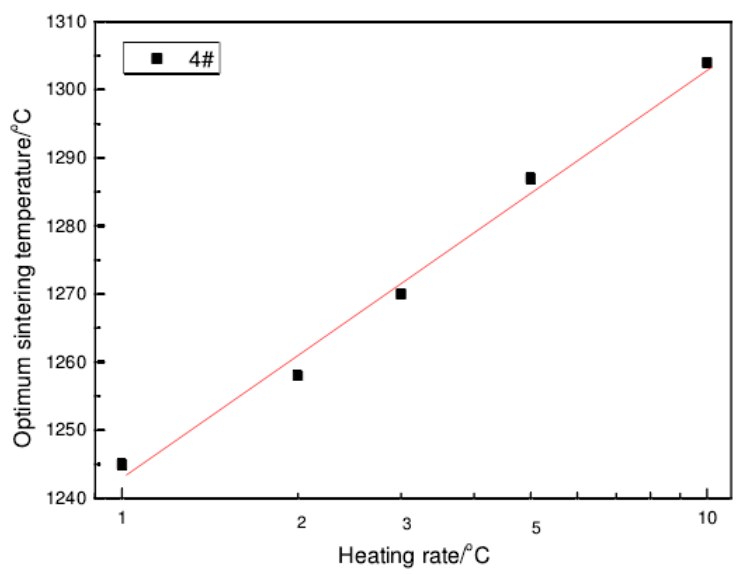

Figure 10 The relationship between ceramic body optimum sintering temperature and heating rate 


\section{CONCLUSION}

From the above research can draw the following conclusions: 1) It is convenient to test the sintering ceramic temperature range the by the dilatometer. The results are also accurate reliable. 2) The ceramic body mainly physical and chemical changes in the sintering process: at $300^{\circ} \mathrm{C}$, exclude dry does not exclude residual moisture. At $300^{\circ} \mathrm{C}-1000^{\circ} \mathrm{C}$, with the decomposition structure of water exclusion and carbonate, body weight loss, volume had no obvious change, kaolinite gradually transformed into metakaolin. At $1000{ }^{\circ} \mathrm{C}$ to sintering temperature, the body begins to shrink. With the increase of temperature, it caused severe contraction of the body densification. 3) The optimum sintering temperature of ceramic materials and the heating rate is linear; the heating rate is higher, the best ceramic firing temperature is high.

\section{ACKNOWLEDGMENTS}

This paper is a case study of the National Nature and the times of the design of the social science planning project of Jiangxi Province in 2012 (12YS203); This paper also is the result of the research on the evolution of Jingdezhen ceramic art education from modern times to the modern times, which is the innovation center of the cultural heritage of Jingdezhen Ceramic Institute.

\section{REFERENCES}

Deng X L, Liu X B, Cai W, et al. The Influence of Sintering Temperature on the Microstructure and Electrical Properties of BiFeO3 Ceramics[J]. Key Engineering Materials, 2014, 602-603:942-946.

Park W U, Zhao J M, Hwang K H, et al. Influence of Sintering Process on the Mechanical Properties of Dental Zirconia Ceramics[J]. Materials Science Forum, 2013, 738-739:542545.

Sivakumar S, Singh R, Loong T H, et al. Effect of Short Time Sintering on the Mechanical Properties of Undoped Zirconia Ceramics[J]. Applied Mechanics \& Materials, 2014, 629:420-425.

Wang B, Cao Q X, Xu G, et al. Sintering Process of Nd: YAG Transparent Ceramic[J]. Applied Mechanics \& Materials, 2013, 281:475-479.

Wang M, Ai X, Zhao J, et al. Modeling and Simulation of Grain Growth of Ceramic Material in Sintering Process[J]. Key Engineering Materials, 2012, 499:253-258. 